\title{
Hepatitis B virus $X$ protein plays an important role in gastric ulcers
}

\author{
PENG-TAO GUO $^{1}$, DONG YANG ${ }^{2}$, ZHE SUN $^{1}$ and HUI-MIAN XU ${ }^{1}$ \\ Departments of ${ }^{1}$ Surgical Oncology, ${ }^{2}$ General Surgery, First Affiliated Hospital \\ of China Medical University, Shenyang 110001, Liaoning, P.R. China
}

Received June 6, 2012; Accepted July 9, 2012

DOI: 10.3892/or.2012.2011

\begin{abstract}
Hepatitis B virus (HBV) infects many individuals globally each year. Researchers usually focus on the relationship between HBV and liver diseases. In this study, we investigated the effects of HBV infection on gastric mucosa. We detected the levels of HBX protein and mRNA in specimens from sixtyfour chronic hepatitis B patients (CHB) with gastric ulcers. We confirmed that HBX could aggravate gastric ulcers according to clinicopathological parameters. In addition, we constructed the pcDNA3.1-HBX plasmid and transfected it into GES-1, a gastric mucosal cell line. The results indicated that HBX could induce apoptosis and $\mathrm{G}_{1}$ arrest in GES-1 cells. Insights into the mechanism of HBX action in GES-1 cells were obtained using western blot analysis.
\end{abstract}

\section{Introduction}

Hepatitis B virus (HBV) infects $\sim 350$ million individuals globally each year and 1.2 million people die from chronic HBV infection, cirrhosis and liver cancer. About 2 billion of the world's population has been infected with the hepatotropic DNA virus at present time (1). HBV contains four identified open reading frames (ORFs) named $\mathrm{C}, \mathrm{S}, \mathrm{P}$, and $\mathrm{X}$ coding for hepatitis $B$ core antigen $(\mathrm{HBcAg})$, hepatitis $B$ surface antigen (HBsAg), hepatitis B envelope antigen ( $\mathrm{HBeAg}$ ), and $\mathrm{X}$ protein, respectively $(2,3)$. $\mathrm{HBcAg}, \mathrm{HBsAg}, \mathrm{HBeAg}$ can be used in the diagnosis of the infection and to determine the severity of the infection (4). The X protein (HBX), which consist of 154 amino acids, contains four regions important for transactivation, and modulation of cytoplasmic signal transduction pathways (5). HBX has received much attention because it can affect apoptosis, gene expression, cell cycle, and cell prolifera-

Correspondence to: Dr Hui-Mian Xu, Department of Surgical Oncology, First Affiliated Hospital of China Medical University, 155 Nanjing North Street, Shenyang 110001, Liaoning, P.R. China E-mail: cmu_directorhm@163.com

Key words: HBV, GES-1, apoptosis, cell cycle, endoplasmic reticulum stress tion in host cells (6-8). Furthermore, the relationship between HBX and many signaling pathways has been demonstrated, such as Ras-Raf MAPK signaling pathway $(9,10)$, JAK-STAT signaling pathway $(11,12)$, PKC signaling pathway $(13,14)$, and SAPK/JNK signaling pathway $(15,16)$. However, whether HBx induced or inhibited apoptosis remains unclear. Previous research has identified that HBX could upregulate survivin a well-known anti-apoptosis protein (17). Others have found HBX is associated with caspase activation and mitochondrial dysfunction (18).

Although chronic infection of HBV has been linked epidemiologically to the development of hepatocellular carcinoma for $>40$ years (19), we neglect another basic problem. As known to us, Hepatitis B virus is transmitted by contact with blood or body fluids of an infected person. Gastric ulcers may cause vascular injury and bleeding, providing an important way for HBV infection. In the last decades, we only pay attention to the relationship between HBV and the liver. We did not note that the lesions caused by HBV in the stomach. Whether HBV can aggravate the injury of gastric ulcer by infecting gastric mucosa epithelial cell remains unclear. This study aimed to determine the role of HBV X protein in gastric tissues and cells.

\section{Materials and methods}

Study population and ethics statement. Sixty-four chronic hepatitis B patients (CHB) with gastric ulcer were recruited from First Hospital of China Medical University in this study from July 2007 to July 2011. The diagnosis of CHB was confirmed by the serological examination of HBsAg for $>6$ months. Tissue specimens were derived from the patients after the resection at the Department of General Surgery. This study was in compliance with the Helsinki Declaration, all patients gave written informed consent for participation, and the procedure was approved by Our University Ethics Committee.

Cell lines. Human gastric mucosa cell line, GES-1, was obtained from the American Type Culture Collection (Bethesda, MD, USA) and grown in RPMI-1640 medium (Hyclone, UT, USA) supplemented with $10 \%$ fetal bovine serum and antibiotics $(100 \mathrm{U} / \mathrm{ml}$ penicillin and $100 \mu \mathrm{g} / \mathrm{ml}$ streptomycin). Cells were maintained in a humidified cell incubator with $5 \% \mathrm{CO}_{2}$ at $37^{\circ} \mathrm{C}$. 
Plasmids and transfection. A full-length ORF of $H B X$ was obtained from gastric ulcer samples by RT-PCR. The primers of $H B X$ were, sense: 5'-CGGAATTCATGGCTGCTAGGC TGTGCTG-3' (EcoRI) and antisense: 5'-CGCGGATCCGG CAGAGGTGAAAAAGTTGC-3' (BamHI) (Takara Dalian, Dalian, China). The cDNA of $H B X$ was cloned into BamHI and $E c o$ RI sites of mammalian expression vector pcDNA3.1. All of the constructs were confirmed by DNA sequencing (Sunbiotech, Beijing, China). Cells were transfected using Lipofectamine $^{\mathrm{TM}} 2000$ (Invitrogen, CA, USA) according to the manufacturer's instructions. HBX-expressing cells were obtained by transfecting with pcDNA3.1-HBX.

Western blot analysis. Tissues and cells were lysed in lysis buffer (20 mM Tris-HCl, $150 \mathrm{mM} \mathrm{NaCl,} 2$ mM EDTA, $1 \%$ Triton-X100) containing a protease inhibitor cocktail (SigmaAldrich, St. Louis, MO). Cell extract protein amounts were quantified using the BCA protein assay kit. Equivalent amounts of protein $(20 \mu \mathrm{g})$ were separated using 12\% SDS-PAGE and transferred to PVDF membrane (Millipore Corporation, Billerica, MA). Western blot was performed using primary antibodies: HBX (Alexis Biochemicals, San Diego, CA), stress-activated protein kinase/JNK antibody (Cell Signaling Technology, Beverly, MA), phospho-stress activated protein kinase/p-JNK ( $\mathrm{Thr}^{183} / \mathrm{Tyr}^{185}$ ) (Cell Signaling Technology), CHOP (abcam), BiP (Cell Signaling Technology), c-jun (Cell Signaling Technology), phosphorylated c-jun (Ser63) (Cell Signaling Technology), and $\beta$-actin (Millipore). Each specific antibody binding was detected with horseradish peroxidase (HRP)-conjugated, respective, secondary antibodies and ECL solutions (Amersham Biosciences, UK).

Semi-quantitative real-time PCR. Total tissue and cellular RNA was isolated using TRIzol reagent (Invitrogen) and was reverse transcribed by using SuperScript II reverse transcriptase (Invitrogen) according to the manufacturer's protocol. Real-time PCR was performed using primers specific for $H B X$ and $G A P D H$. Real-time PCR analysis was performed on the ABI Prism 7500 sequence detection system (Applied Biosystems, Foster, CA) using the SYBR Green PCR Master mixture (Takara, Dalian). The PCR conditions were: one cycle at $95^{\circ} \mathrm{C}$ for $10 \mathrm{~min}$ followed by 40 cycles at $95^{\circ} \mathrm{C}$ for $15 \mathrm{sec}$ and at $60^{\circ} \mathrm{C}$ for $1 \mathrm{~min}$. The following primer sets were used: HBX sense: 5'-GGCAGAGGTGAAAAAGTTGC-3', antisense: 5'-GGC AGAGGTGAAAAAGTTGC-3'; GAPDH sense: 5'-GAA GGTGAAGGTCGGAGT-3', antisense: 5'-CATGGGTGG AATCATATTG GAA-3'. Relative quantitation was calculated by $\Delta \Delta \mathrm{Ct}$ method. Each reaction was repeated independently at three times in triplicate.

Immunohistochemical staining (IHC). Immunohistochemistry was used to detect the expression of HBX protein in gastric ulcer samples. The study population included 64 patients. Immunohistochemical staining was performed on $4-\mu \mathrm{m}$ sections obtained from formalin-fixed, paraffin-embedded blocks. Endogenous peroxidase activity was blocked with $3 \%$ hydrogen peroxide for $30 \mathrm{~min}$. Antigen retrieval was carried out in citrate buffer $(10 \mathrm{mM}, \mathrm{pH} 6.0)$ for $30 \mathrm{~min}$ at $95^{\circ} \mathrm{C}$ in a pressure cooker. Anti-HBX (Alexis Biochemicals) at 1:500 was applied incubated at $4^{\circ} \mathrm{C}$ overnight. Afterward, sections
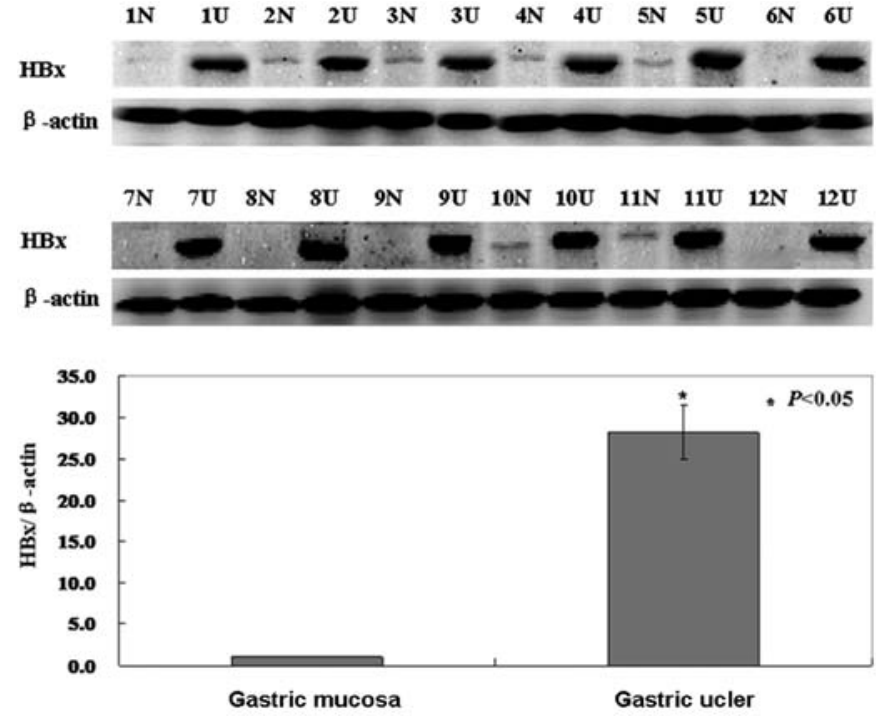

Figure 1. Western blotting for HBX proteins in specimens. HBX proteins expression level was higher in ulcers than matched normal tissues $(\mathrm{P}<0.05)$ $\mathrm{N}$ : normal, U: ulcer. $\beta$-actin was used as an internal control.

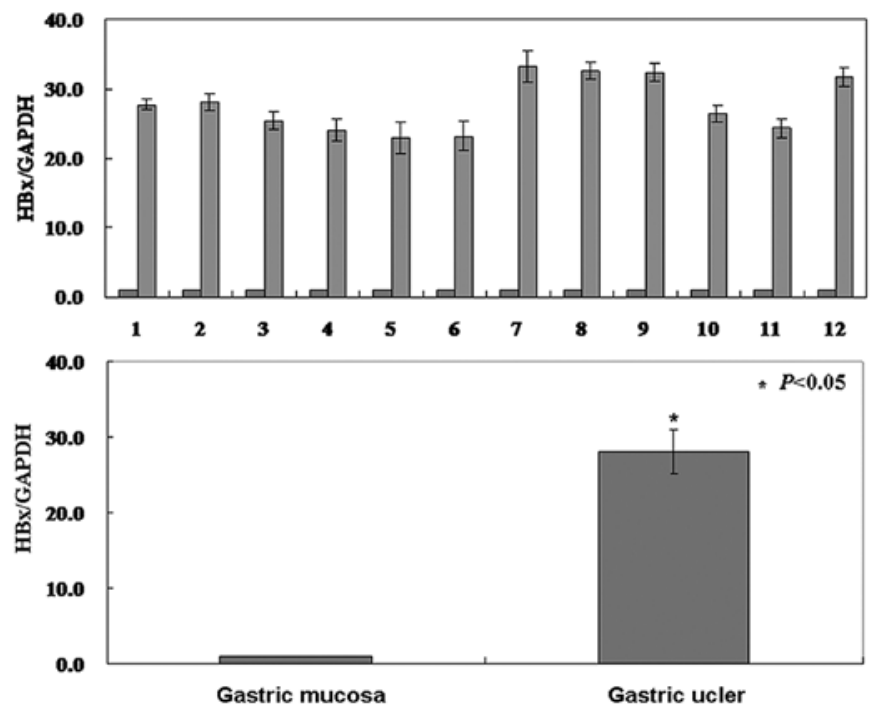

Figure 2. The level of HBX mRNA was measured in specimens using realtime PCR. The level of HBX mRNA was higher in ulcers than matched normal tissues $(\mathrm{P}<0.05)$. N, normal; $\mathrm{U}$, ulcer. GAPDH was used as an internal control.

were incubated with a biotinylated secondary antibody and then exposed to a streptavidin complex (HRP). Positive reactions were visualized with 3,3'-diaminobenzidine tetrahydrochloride (DAB, Sigma), followed by counterstaining with hematoxylin. Normal tissue was used as a control. Sections treated without primary antibodies were used as negative controls.

3-[4,5-Dimethylthiazol-2-yl]-2, 5-diphenyltetrazolium bromide (MTT) assay. The proliferation rate of HBX-expressing cells and control cells were measured by MTT assay. Briefly, HBX-expressing cells or control cells were plated at a density of $1 \times 10^{3} /$ well in 96 -well plates. After incubation of $48 \mathrm{~h}, 0.5 \mathrm{mg} / \mathrm{ml}$ MTT was added (Sigma). Four hours later, the medium was replaced with $100 \mu 1$ dimethylsulfoxide (DMSO) (Sigma). 

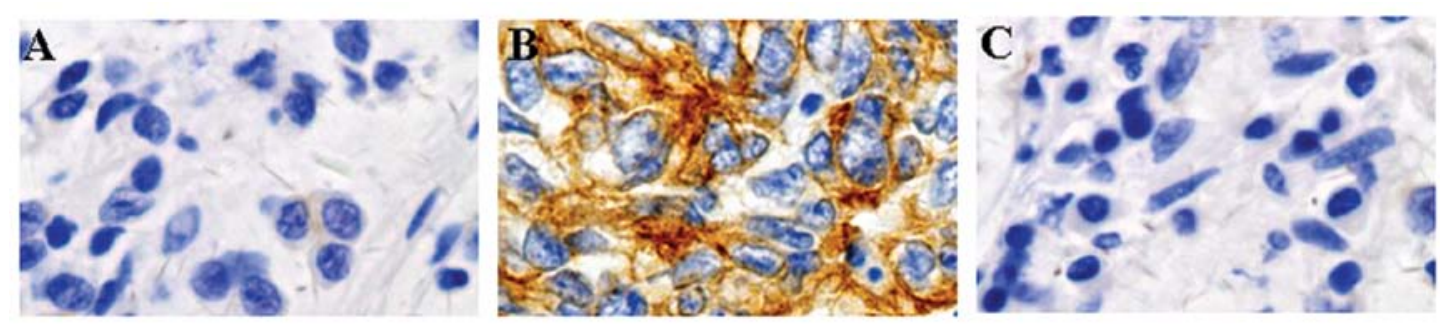

Figure 3. Representative results of two paires of gastric ulcer and corresponding normal tissue by immunohistochemical staining with anti-HBX antibody. (A) paired normal tissue (B) gastric ulcer tissue (C) negative control. HBX was stained yellow with granules and localized to the cytoplasm. The nuclei were counterstained with hematoxylin.

Absorbance Optical density (OD) of each well was determined at $490 \mathrm{~nm}$ of wavelength with subtraction of baseline reading. Each time point was repeated six times and the mean and standard errors were calculated.

4'-6-Diamidino-2-phenylindole (DAPI) staining assay. DAPI staining was applied for determining the apoptotic cells. Cells at a density of $1 \times 10^{5}$ cells/well were maintained on six-well plates and then were treated under the normal culture condition. Cells in each well were individually fixed in $4 \%$ (v/v) paraformaldehyde (Sigma) for $15 \mathrm{~min}$ and then stained using DAPI (Invitrogen) for apoptotic cells. Cells were then examined and photographed using a fluorescence microscope (Olympus CX71, Japan).

Cell cycle and apoptosis analysis. The gastric mucosal GES-1 cells $\left(3 \times 10^{5} /\right.$ well), were plated and incubated overnight. The control and treated cells were trypsinized, collected in PBS and fixed on ice with $1 \%$ paraformaldehyde, followed by $70 \%$ cold ethanol. After treatment with $10 \mu \mathrm{g} / \mathrm{ml}$ RNase, the cells were stained with $50 \mu \mathrm{g} / \mathrm{ml}$ propidium iodide (PI, KeyGEN, Nanjing, China) for $15 \mathrm{~min}$ at room temperature for cell cycle analysis. The apoptotic cells were detected with AnnexinV-FITC/PI double staining. The cells were trypsinized and stained with Annexin V-FITC and PI following the manufacturer's instructions for the Apoptosis Assay kit (KeyGEN). The stained cells were analyzed by flow cytometry. Data analysis was performed with CellQuest software (BD Biosciences, MD).

Statistical analysis. All experiments were done three times in triplicate, and the results were expressed as means \pm SD (standard deviation). P-values $<0.05$ were considered to statistically significant. All statistical analyses were performed with SPSS software (version 16.0; SPSS Inc., Chicago, IL, USA).

\section{Results}

The levels of $H B X m R N A$ and protein were evaluated in gastric ulcer specimens from 64 chronic hepatitis $B$ patients $(\mathrm{CHB})$. Western blotting was carried out to investigate the protein status of HBX in gastric ulcer specimens. As shown in the results, the level of HBX protein was higher in gastric ulcers than that in normal tissue $(\mathrm{P}<0.05$, Fig. 1). To examine the relationship between the level of HBX protein and the level of HBX transcription, real-time PCR of HBX mRNA was carried out in gastric ulcer specimens. The results showed that the level of
HBX mRNA was also higher than normal tissue and coincident with the level of protein $(\mathrm{P}<0.05$, Fig. 2).

Correlation between HBX expression and clinicopathological features in gastric ulcers. The immunostaining for HBX was only localized in the cytoplasm. HBX protein was highly expressed in gastric ulcer specimens, but not in normal parts of the specimens (Fig. 3). We then analyzed the potential relationship between the expression of HBX and the clinicopathological characteristics of these patients. The results are summarized in Table I. No correlation was found with gender, age, intake of alcohol, ulcer location, or ulcer stage ( $\mathrm{P}>0.05)$. However, HBx expression was significantly associated with atrophy, metaplasia and bleeding $(\mathrm{P}<0.05)$.

HBX expressed in human gastric mucosa cell line GES-1. In order to study the role that HBX plays in human gastric mucosa cell line GES-1, we examined the effects of exogenous HBX expression in GES-1. To this end, we constructed an HBX-expressing plasmid, pCDNA-3.1-HBX, and transfected it into GES-1 cells. The levels of HBX mRNA and protein increased upon transfection, compared to the levels observed in human gastric mucosa cell line GES-1 (Fig. 5).

The effects of HBX on GES-1 cells. MTT assays were performed, and growth inhibition curves were generated $(\mathrm{P}<0.05$, Fig. 4A). Proliferative ratio of the human gastric mucosa GES-1 cells was inhibited by HBX expression. DAPI staining showed morphological changes in the nucleus after HBX transfection. Fig. 4B shows nuclear condensation in apoptotic cells. AnnexinV-FITC and PI double staining was performed to detect apoptotic cells quantitatively. The apoptotic ratio of the cells transfected with pCDNA-3.1-HBX was 6-7 times higher than that of untransfected cells $(\mathrm{P}<0.05$, Fig. 4C). When cell cycles of transfected and untransfected cells were examined using PI staining, the ratio of cells in the $\mathrm{G}_{1}$ phase increased in transfected cells versus untransfected cells $(\mathrm{P}<0.05$, Fig. 4D).

The mechanism of HBX induced-apoptosis in GES-1 cells. Given that ER stress is highly correlated with the promotion of apoptosis, in this study we examined the changes of ER-stress mediated apoptotic pathways in GES-1 after pCDNA-3.1-HBX transfection. As shown in Fig. 5, expression of ER stress molecules (BiP and CHOP) was significantly increased in HBX-transfected cells. Activation of JNK pathway in GES-1 
Table I. Relationship between HBx expression and clinicopathological parameters of gastric ulcers.

\begin{tabular}{|c|c|c|c|c|c|c|c|c|}
\hline \multirow{2}{*}{$\begin{array}{l}\text { Clinicopathological } \\
\text { features }\end{array}$} & \multirow[b]{2}{*}{$\mathrm{n}$} & \multicolumn{7}{|c|}{ HBx expression } \\
\hline & & - & + & ++ & +++ & PR (\%) & $\chi^{2}$ value & $\mathrm{P}$ \\
\hline Gender & & & & & & & 0.986 & 0.982 \\
\hline Female & 26 & 4 & 2 & 11 & 9 & 84.6 & & \\
\hline Male & 38 & 5 & 6 & 14 & 13 & 86.8 & & \\
\hline Age (years) & & & & & & & 0.882 & 0.498 \\
\hline$<45$ & 22 & 3 & 3 & 10 & 6 & 86.4 & & \\
\hline$\geq 45$ & 42 & 6 & 5 & 15 & 16 & 85.7 & & \\
\hline Intake of alcohol & & & & & & & 5.266 & 0.510 \\
\hline No & 23 & 1 & 5 & 8 & 9 & 95.7 & & \\
\hline Yes & 41 & 8 & 3 & 17 & 13 & 80.5 & & \\
\hline Atrophy & & & & & & & 7.866 & 0.048 \\
\hline- & 16 & 2 & 1 & 3 & 10 & 87.5 & & \\
\hline+ & 48 & 7 & 7 & 22 & 12 & 85.4 & & \\
\hline Metaplasia & & & & & & & 11.00 & 0.012 \\
\hline- & 19 & 4 & 2 & 2 & 11 & 78.9 & & \\
\hline+ & 45 & 5 & 6 & 23 & 11 & 88.9 & & \\
\hline Bleeding & & & & & & & 12.34 & 0.006 \\
\hline- & 24 & 2 & 5 & 4 & 13 & 91.7 & & \\
\hline+ & 40 & 7 & 3 & 21 & 9 & 82.5 & & \\
\hline Location & & & & & & & 3.305 & 0.951 \\
\hline Antrum or angle & 18 & 2 & 2 & 7 & 7 & 88.8 & & \\
\hline Lower body & 15 & 3 & 1 & 6 & 5 & 80.0 & & \\
\hline Mid-body & 16 & 1 & 2 & 7 & 6 & 93.8 & & \\
\hline Upper body & 15 & 3 & 3 & 5 & 4 & 80.0 & & \\
\hline Stage & & & & & & & 6.295 & 0.974 \\
\hline $\mathrm{A} 1$ & 11 & 1 & 1 & 4 & 5 & 90.9 & & \\
\hline A2 & 8 & 1 & 1 & 3 & 3 & 87.5 & & \\
\hline H1 & 9 & 1 & 1 & 5 & 2 & 88.8 & & \\
\hline $\mathrm{H} 2$ & 12 & 2 & 2 & 2 & 6 & 83.3 & & \\
\hline $\mathrm{S} 1$ & 11 & 2 & 2 & 5 & 2 & 81.8 & & \\
\hline $\mathrm{S} 2$ & 13 & 2 & 1 & 6 & 4 & 84.6 & & \\
\hline
\end{tabular}

$\chi^{2}$ value, Chi-squared distribution.

cells transfected with pCDNA-3.1-HBX was confirmed using a phosphorylated JNK-specific antibody and by detecting the phosphorylation of c-jun (Fig. 5). No significant changes of JNK and c-jun were detected in transfected cells. These results indicate that JNK phosphorylation is a crucial event controlling HBX-induced apoptosis. We also confirmed that caspase-3 was activated in transfected cells.

\section{Discussion}

HBV infection is a major risk factor of human chronic liver disease and is strongly associated with hepatocellular carcinogenesis (HCC) (20). Although the relationship between HBV infection and chronic liver disease has been identified, the effects of HBV infection on gastric problems remain unclear. $\mathrm{HBX}$ is a $17-\mathrm{kDa}$ transcriptional co-activator that plays a significant role in the regulation of genes involved in inflammation and cell survival (21). In our studies, HBX was found to be highly expressed in gastric ulcer specimens from chronic hepatitis B patients. We found that HBX expression was significantly associated with atrophy, metaplasia and bleeding. These results suggested that HBV could infect gastric mucosa and aggravate gastric mucosal injury.

Some previous studies have suggested that HBX can activate apoptotic pathways and induce apoptosis (22-25). However, opposing the pro-apoptotic activity of HBX was 

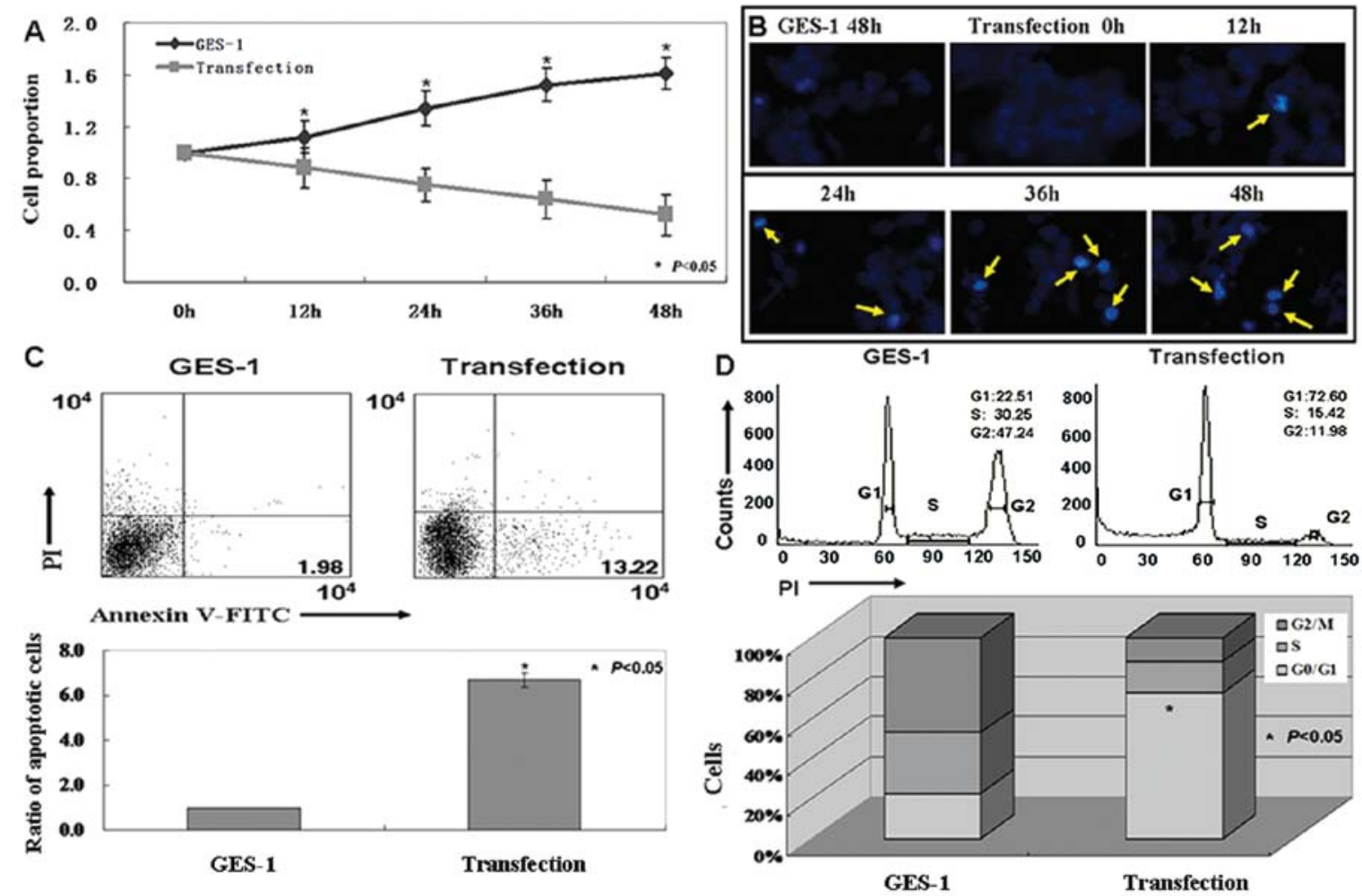

Figure 4. The effects of HBX on GES-1. (A) The growth curve of cell lines was measured using the MTT assay. (B) Apoptotic body formation was observed under a fluorescence microscope after DAPI staining. Yellow arrows indicate nuclear condensation. (C) Apoptotic ratio of cells transfected with HBX was determined from Annexin-V/PI double-staining assays. The histogram indicates statistically significant results (P<0.05). (D) Propidium iodide staining showed changes in the cell cycle. The histogram shows the results has statistical significant $(\mathrm{P}<0.05)$.
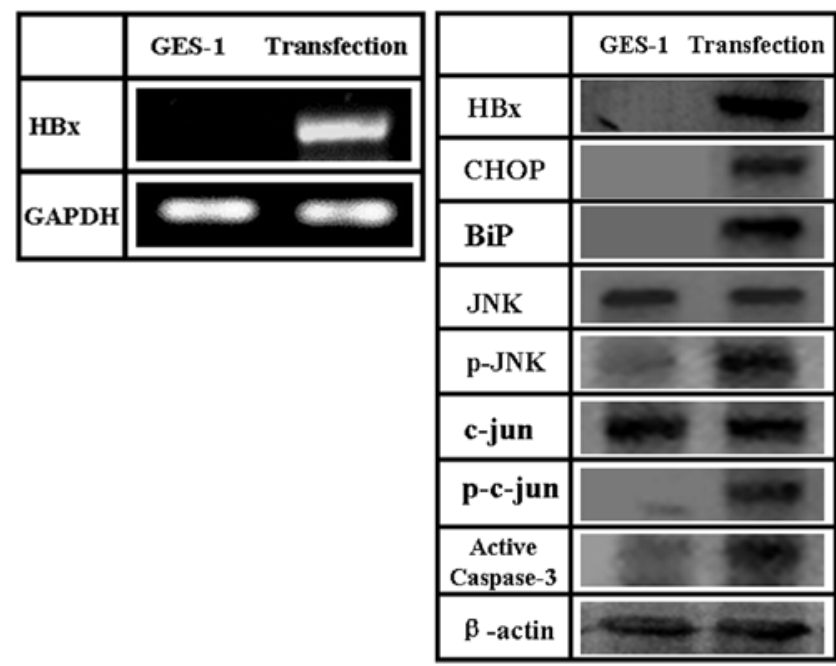

Figure 5. The mRNA level of HBX was determined by RT-PCR. GAPDH was used as an internal control (left panel). HBX provokes ER stress and further activates JNK signaling pathway in GES-1 (right panel). Each experiment was performed in triplicate.

observed in other studies (15,26-28). The effects of HBX on apoptosis are not entirely understood. In our studies, we confirmed that HBX could induce GES-1 cells to apoptosis. GES-1 cells transfected with pCDNA-3.1-HBX exhibited apoptosis and $\mathrm{G}_{1}$ arrest. The results of our study are consistent with two other studies which concluded that HBX inhibited hepatocyte regeneration $(29,30)$. Wu et al (29) found that HBX protein blocks $\mathrm{G}_{1} / \mathrm{S}$ transition of the hepatocyte cell cycle progression. The results of Gearhart and Bouchard (31) also suggest that HBX uses mitochondrial-dependent calcium signaling to cause hepatocytes to exit $\mathrm{G}_{0}$ but stall in $\mathrm{G}_{1}$.

In previous studies, HBX was shown to be involved in many cell signaling transduction pathways, such as Ras-Raf MAPK signaling pathway, JAK-STAT signaling pathway, PKC signaling pathway, and SAPK/JNK signaling pathway (9-16). HBX activates AP-1 via a pathway that is mediated by the activation of ERK and JNK $(32,33)$. Kong et al (34) have demonstrated that activation of AP-1 and JNK was inhibited in the cells after siRNA treatment. In order to detect the mechanism of HBX in GES-1, we carried out western blot to analyze the changes of related signaling pathways. Consistent with previous studies, we found that HBX induced apoptosis in GES-1 though the JNK signaling pathway. We confirmed that HBX was able to efficiently provoke endoplasmic reticulum (ER) stress in GES-1. ER stress can be induced by the unfolded protein response (UPR), which is activated in a number of disease processes, such as obesity, diabetes, heart disease, cancer, and viral infection $(35,36)$. Previous studies have demonstrated that alteration of the levels of the ER molecular chaperone GRP78/BiP can inhibit tumor growth in vivo (37). Others studies also confirmed that ER stress-induced apoptosis is highly dependent on the upregulation of the UPR-inducible transcription factor CHOP (38). Consistent with previous studies, we found that the levels of BiP and CHOP in GES-1 cells were higher than untreated ones. These results indicated that HBX could provoke ER stress and further activate JNK signaling pathway in GES-1. 
In conclusion, our results demonstrated that the infection of $\mathrm{HBV}$ is involved in progression of gastric ulcers. In addition, HBX acts as a positive regulator in the JNK signaling pathway. These findings may provide important information in understanding the role of the HBV infection in gastric ulcers.

\section{Acknowledgements}

We thank Dr Miao Yu for technical assistance.

\section{References}

1. Shepard CW, Simard EP, Finelli L, et al: Hepatitis B virus infection: epidemiology and vaccination. Epidemiol Rev 28: $112-125,2006$.

2. Robinson WS: Molecular events in the pathogenesis of hepaDNA virus-associated hepatocellular carcinoma. Annu Rev Med 45: 297-323, 1994.

3. Yee JK: A liver-specific enhancer in the core promoter region of human hepatitis B virus. Science 246: 658-661, 1989.

4. Gitlin N: Hepatitis B: diagnosis, prevention, and treatment. Clin Chem 43: 1500-1506, 1997.

5. Tang H, Oishi N, Kaneko S, et al: Molecular functions and biological roles of hepatitis B virus X protein. Cancer Sci 97: 977-983, 2006

6. Liang X, Liu Y, Zhang Q, et al: Hepatitis B virus sensitizes hepatocytes to TRAIL-induced apoptosis through Bax. J Immunol 178: 503-510, 2007.

7. Mukherji A, Janbandhu VC and Kumar V: HBx-dependent cell cycle deregulation involves interaction with cyclin E/A-cdk2 complex and destabilization of p27Kip1. Biochem J 401: 247-256, 2007.

8. Shan C, Xu F, Zhang S, et al: Hepatitis B virus X protein promotes liver cell proliferation via a positive cascade loop involving arachidonic acid metabolism and p-ERK1/2. Cell Res 20: 563-575, 2010

9. Stockl L, Berting A, Malkowski B, et al: Integrity of c-Raf-1/ MEK signal transduction cascade is essential for hepatitis B virus gene expression. Oncogene 22: 2604-2610, 2003.

10. Tarn C, Lee S, Hu Y, et al: Hepatitis B virus X protein differentially activates RAS-RAF-MAPK and JNK pathways in X-transforming versus non-transforming AML12 hepatocytes. J Biol Chem 276: 34671-34680, 2001

11. Lee YH and Yun Y: HBx protein of hepatitis B virus activates Jak1-STAT signaling. J Biol Chem 273: 25510-25515, 1998.

12. Bock CT, Toan NL, Koeberlein B, et al: Subcellular mislocalization of mutant hepatitis B X proteins contributes to modulation of STAT/SOCS signaling in hepatocellular carcinoma. Intervirology 51: 432-443, 2008

13. Cong YS, Yao YL, Yang WM, et al: The hepatitis B virus $\mathrm{X}$-associated protein, XAP3, is a protein kinase C-binding protein. J Biol Chem 272: 16482-16489, 1997.

14. Kekulé AS, Lauer U, Weiss L, et al: Hepatitis B virus transactivator HBx uses a tumor promoter signaling pathway. Nature 361: 742-745, 1993.

15. Diao J, Khine AA, Sarangi F, et al: X protein of hepatitis B virus inhibits Fas-mediated apoptosis and is associated with up-regulation of the SAPK/JNK pathway. J Biol Chem 276: 8328-8340, 2001.

16. Oh JC, Jeong DL, Kim IK, et al: Activation of calcium signaling by hepatitis B virus-X protein in liver cells. Exp Mol Med 35: 301-309, 2003.

17. Zhang X, Dong N, Yin L, et al: Hepatitis B virus X protein upregulates survivin expression in hepatoma tissues. J Med Virol 77: 374-381, 2005

18. Takada S, Shirakata Y, Kaneniwa N, et al: Association of hepatitis B virus X protein with mitochondria causes mitochondrial aggregation at the nuclear periphery, leading to cell death. Oncogene 18: 6965-6973, 1999.
19. Sherlock S, Fox RA, Niazi SP, et al: Chronic liver disease and primary liver cell cancer with hepatitis-associated (Australia) antigen in serum. Lancet 1: 1243-1247, 1970.

20. Kim CM, Koike K, Saito I, et al: HBx gene of hepatitis B virus induces liver cancer in transgenic mice. Nature 351: 317-320, 1991.

21. Gottlob K, Pagano S, Levrero M, et al: Hepatitis B virus X protein transcription activation domains are neither required nor sufficient for cell transformation. Cancer Res 58: 3566-3570, 1998.

22. Miao J, Chen GG, Chun SY, et al: Hepatitis B virus X protein induces apoptosis in hepatoma cells through inhibiting Bcl-xL expression. Cancer Lett 236: 115-124, 2006.

23. Chirillo P, Pagano S, Natoli G, et al: The hepatitis B virus X gene induces p53-mediated programmed cell death. Proc Natl Acad Sci USA 94: 8162-8167, 1997.

24. Shintani Y, Yotsuyanagi $\mathrm{H}$, Moriya $\mathrm{K}$, et al: Induction of apoptosis after switch-on of the hepatitis $\mathrm{B}$ virus $\mathrm{X}$ gene mediated by the Cre/loxP recombination system. J Gen Virol 80: 3257-3265, 1999.

25. Su F and Schneider RJ: Hepatitis B virus HBx protein sensitizes cells to apoptotic killing by tumor necrosis factor alpha. Proc Natl Acad Sci USA 94: 8744-8749, 1997.

26. Lee YI, Kang-Park S, Do SI, et al: The hepatitis B virus-X protein activates a phosphatidylinositol 3-kinase-dependent survival signaling cascade. J Biol Chem 276: 16969-16977, 2001.

27. Pan J, Duan LX, Sun BS, et al: Hepatitis B virus $X$ protein protects against anti-Fas-mediated apoptosis in human liver cells by inducing NF-kappa B. J Gen Virol 82: 171-182, 2001.

28. Shih WL, Kuo ML, Chuang SE, et al: Hepatitis B virus X protein inhibits transforming growth factor-beta-induced apoptosis through the activation of phosphatidylinositol 3-kinase pathway. J Biol Chem 275: 25858-25864, 2000.

29. Wu BK, Li CC, Chen HJ, et al: Blocking of G1/S transition and cell death in the regenerating liver of Hepatitis $B$ virus $X$ protein transgenic mice. Biochem Biophys Res Commun 340: 916-928, 2006.

30. Tralhao JG, Roudier J, Morosan S, et al: Paracrine in vivo inhibitory effects of hepatitis B virus X protein (HBx) on liver cell proliferation: An alternative mechanism of $\mathrm{HBx}$-related pathogenesis. Proc Natl Acad Sci USA 99: 6991-6996, 2002.

31. Gearhart TL and Bouchard MJ: Replication of the hepatitis B virus requires a calcium-dependent $\mathrm{HBx}$-induced $\mathrm{G} 1$ phase arrest of hepatocytes. Virology 407: 14-25, 2010.

32. Jacqueline B, Fei S, Margherita D, et al: Hepatitis B virus HBx protein induces transcription factor AP-1 by activation of extracellular signal-regulated and c-Jun N-terminal mitogen-activated protein kinases. J Virol 70: 4978-4985, 1996.

33. Nijhara R, Jana SS, Goswami SK, et al: Sustained activation of mitogen-activated protein kinases and activator protein 1 by the hepatitis B virus $\mathrm{X}$ protein in mouse hepatocytes in vivo. J Virol 75: 10348-10358, 2001.

34. Kong GY, Zhang JP, Zhang S, et al: Hepatitis B virus X protein promotes hepatoma cell proliferation via upregulation of MEKK2. Acta Pharmacol Sin 32: 1173-1180, 2011

35. Kim I, Xu W and Reed JC: Cell death and endoplasmic reticulum stress: disease relevance and therapeutic opportunities. Nat Rev Drug Discov 7: 1013-1030, 2008.

36. Medigeshi GR, Lancaster AM, Hirsch AJ, et al: West Nile virus infection activates the unfolded protein response, leading to CHOP induction and apoptosis. J Virol 81: 10849-10860, 2007.

37. Moenner M, Pluquet O, Bouchecareilh M, et al: Integrated endoplasmic reticulum stress responses in cancer. Cancer Res 67: 10631-10634, 2007.

38. Tamaki N, Hatano E, Taura K, et al: CHOP deficiency attenuates cholestasis-induced liver fibrosis by reduction of hepatocyte injury. Am J Physiol Gastrointest Liver Physiol 294: G498G505, 2008. 